\title{
PERFIL SÓCIO DEMOGRÁFICO E DAS ATIVIDADES AGRÍCOLAS DE MANEJO E PRODUÇÃO DE AGRICULTORES FAMILIARES INSCRITOS NO PROGRAMA DE AQUISIÇÃO DE ALIMENTOS-PAA, DO MUNICÍPIO DE UBÁ-MG ${ }^{1}$
}

Lucimar Moreira Guimarães Batista ${ }^{1}$, Sônia Machado Rocha Ribeiro², Ricardo Henrique Silva Santos ${ }^{3}$, Andréia Queiroz Ribeiro ${ }^{4}$, Raquel Maria Araújo do Amaral $^{5}$, Rogério de Paula Lana ${ }^{6}$, Gisely Peron

Gasparoni $^{7}$

\begin{abstract}
RESUMO - A agricultura familiar possui potencial econômico, ambiental e social, que nos últimos anos tem sido prestigiado e fortalecido por programas governamentais que estimulam e incentivam ações de Segurança Alimentar e Nutricional-SAN. O Programa de Aquisição de Alimentos-PAA foi instituído em 2003, como uma das ações do Programa Fome Zero visando fortalecimento da agricultura familiar. Objetivo: Caracterizar o perfil sócio demográfico e as atividades agrícolas de manejo e produção dos agricultores familiares, inscritos no PAA, do Banco de Alimentos-BA, do município de Ubá-MG. Resultados: A amostra foi representativa com 58 agricultores familiares de ambos os sexos, acima de 19 anos predominando: sexo masculino, nível de escolaridade de ensino fundamental e estado civil casado. A maioria depende da mão-de-obra familiar; o destino da produção para autoconsumo, comercialização com PAA e mercado local; possui pose da terra. Com relação às práticas de produção e manejo manuais destacaram-se a colheita e a capina. Concluindo, é importantíssimo estimular práticas de manejo e produção que possam contribuir para segurança ocupacional e para segurança alimentar e nutricional dos agricultores familiares e de suas famílias, podendo também contribuir para sustentabilidade ambiental, social e econômica dos atores envolvidos em todo sistema agroalimentar.
\end{abstract}

Palavras chave: agricultura familiar, políticas públicas, Programa de Aquisição de Alimentos, segurança alimentar e nutricional.

\section{SOCIO DEMOGRAPHIC PROFILE AND AGRICULTURAL MANAGEMENT ACTIVITIES AND FARMERS FAMILY ENROLLED IN PROGRAMA DE AQUISIÇÃO DE ALIMENTOS-PAA, THE CITY OF UBA-MG}

\begin{abstract}
The Family farming has a recognized economic, environmental and social potential, which in recent years has been prestigious and strengthened by government programs that stimulate and encourage Food Security and Nutrition actions SAN-increasing food availability. The PAA-Programa de Aquisição de Alimentos was established in 2003 as one of the actions of the Zero Hunger Program aiming at strengthening family farming. Objective: To characterize the socio-demographic profile and the agricultural activities of management and production of family farmers enrolled in the PAA, the Banco de Alimentos-BA, the city of Ubá-MG. Results: A representative sample of 58 family farmers, men and women above 19 years with prevalence: male, elementary school level of education and married marital status. Most depends on hand
\end{abstract}

\footnotetext{
${ }^{1}$ Recebido para publicação em 04/10/2015 e aprovado em 14/12/2015.

${ }^{2}$ Recebido para publicação em 04/10/2015 e aprovado em 14/12/2015.

${ }^{3}$ Recebido para publicação em 04/10/2015 e aprovado em 14/12/2015.

${ }^{4}$ Recebido para publicação em 04/10/2015 e aprovado em 14/12/2015.

${ }^{5}$ Recebido para publicação em 04/10/2015 e aprovado em 14/12/2015.

${ }^{6}$ Recebido para publicação em 04/10/2015 e aprovado em 14/12/2015.

${ }^{7}$ Recebido para publicação em 04/10/2015 e aprovado em 14/12/2015.
} 
labor family, and the fate of its production is own consumption, trade with PAA and the local market, in addition to land tenure. With regard to production practices and manual handling stood out harvesting and weeding. In conclusion, it is very important the stimulus management and production practices that can contribute to occupational safety and food and nutrition security of farmers and their families and may also contribute to environmental, social and economic sustainability of the actors involved in whole food system.

Keywords: family farming, "food acquisition program", food and nutritional security, public policies.

\section{INTRODUÇÃO}

Na década de 70, em países em desenvolvimento como o Brasil, a estrutura agrária foi caracterizada pela concentração da posse da terra por poucos proprietários que detinham mais recursos financeiros e tecnologias mais avançadas (SILVA, 1995). No Brasil, o aumento da importação dos agroquímicos, da instalação de indústrias produtoras e formuladoras de agrotóxicos e de fertilizantes, e do estímulo do governo com crédito rural para o consumo dos mesmos resultou estratégias de desenvolvimento limitadas em sua capacidade de promover a equidade e a sustentabilidade dos sistemas de produção agrícolas (ALTIERI, 1989; MEIRELLES, 1996).

Ao longo da década de 90, o consumo de agroquímicos ou agrotóxicos no mundo cresceu $93 \%$. No Brasil, o crescimento foi de $190 \%$, conforme um dossiê divulgado pela Associação Brasileira de Saúde Coletiva-ABRASCO (Carneiro, 2012). Em 2008, o Brasil assumiu o posto de maior mercado mundial de 'defensivos agrícolas' - termo usado-para amenizar a negatividade de "agrotóxico" (SILVA, 2005; CARNEIRO, 2012).

A agricultura familiar no Brasil desenvolveu-se à margem desse processo modernizante gerado pela política desenvolvimentista e fortemente condicionada pela Revolução Verde. Porém, a partir de estratégias próprias ela tem conseguido se sobressair, ainda que com grandes dificuldades devido ao descaso histórico e a incompatibilização das políticas governamentais (ALTIERI, 1989).

A agricultura familiar tem como unidade básica: a produção familiar. A sustentabilidade econômica está no aproveitamento múltiplo dos recursos naturais, unindo atividades econômicas voltadas ao autoconsumo e à comercialização (SILVA, 2010).

Segundo o Censo Agropecuário de 2006, foram identificados 4.367.902 estabelecimentos de agricultura familiar, representando $84,4 \%$ do total, os quais ocupam apenas $24,3 \%$ da área agrícola brasileira. Neste censo, dados apontam que a agricultura familiar foi responsável por: $87 \%$ da produção nacional de mandioca, $70 \%$ da produção de feijão, $46 \%$ do milho, $38 \%$ do café, $34 \%$ do arroz, $58 \%$ do leite, $59 \%$ de suínos, $50 \%$ das aves, $30 \%$ de bovinos e, ainda $21 \%$ do trigo, e $16 \%$ de soja (NETO, 2012).

A Segurança Alimentar e Nutricional-SAN é definida como "a realização do direito de todos ao acesso regular e permanente a alimentos de qualidade e em quantidade suficiente, sem comprometer o acesso a outras necessidades essenciais, tendo como base práticas alimentares promotoras de saúde, que respeitem a diversidade cultural e que sejam social, econômica e ambientalmente sustentáveis" (BRASIL, 2006; MALUF, 2007). As ações de Segurança Alimentar e Nutricional podem ser implementadas a partir da agricultura familiar, visto que, a SAN aumenta a disponibilidade de alimentos e a variabilidade de nutrientes à população, favorecendo a comercialização destes alimentos em nível regional, além de contribuir para hábitos alimentares saudáveis e consequentemente, melhorar a qualidade da alimentação.

A agricultura familiar possui um reconhecido potencial econômico, ambiental e social, o qual tem sido nos últimos anos, prestigiado e fortalecido por programas governamentais que estimulam e incentivam a produção e o beneficiamento de seus produtos (SILVA, 2010). Assim, a agricultura familiar começou a ser vista como uma alternativa de desenvolvimento sustentável, necessitando de políticas públicas específicas para seu fortalecimento.

Mecanismos de gestão social das políticas públicas foram introduzidos pela Constituição de 1988, com objetivo de democratizar o acesso dos beneficiários aos recursos públicos do meio rural e urbano (JUNQUEIRA, 2008). Por meio da "Ação da Cidadania Contra a Fome e a Miséria e Pela Vida”, um movimento social articulado por debates em 1992, implementou 
no Brasil, a partir de 1993, a "Campanha Nacional de Combate à Fome”, liderada pelo sociólogo Herbert de Souza. Esse movimento formou muitos comitês em todo país. Assim, mobilizações populares, parcerias entre governos e sociedade civil, e lutas pelos direitos sociais, tornaram se frequentes na sociedade brasileira (MATTEI, 2007). Neste contexto, foi criado, em 1996 o Programa Nacional de Fortalecimento da Agricultura FamiliarPRONAF. Essa política foi essencial para a agricultura familiar, pois direcionou o crédito à produção e ao investimento agrícola (JUNQUEIRA, 2008).

No ano de 2002, por meio do Projeto Fome ZeroPFZ, a sociedade brasileira e os grupos em vulnerabilidade social, foram contemplados com ações de SAN por parte do poder público. Estas foram instituídas pelo PFZ referentes aos aspectos de desenvolvimento econômico e social baseado na produção alimentar estimulando a revalorização de métodos tradicionais de manejo e gestão ambiental apoiado nos conhecimentos acumulados pelas populações locais. A partir destas características, a agricultura familiar, tornou-se uma opção com potencial de construir sistemas de produção agrícolas de alimentos auto-sustentáveis e mais diversificados, que promovam o acesso à alimentação adequada e saudável (SANTOS, 2010).

O Programa de Aquisição de Alimentos-PAA foi instituído pelo artigo 19 da Lei n. ${ }^{\circ} 10.696$ de 2 de julho de 2003, atualizado pela Lei ${ }^{\circ} 12.512$, de 14 de outubro de 2011 com regulamentação via Decreto $n^{\circ} 7.775$, de 04/07/2012 (BRASIL, 2003). Este é coordenado pela Companhia Nacional de Abastecimento-CONAB e acompanhado ao longo de sua formulação pelo Conselho Nacional de Segurança Alimentar e Nutricional-CONSEA e organizações da sociedade civil. O PAA é considerado como uma das principais ações estruturantes do Programa Fome Zero, constitui um mecanismo complementar ao Programa Nacional de Agricultura Familiar-PRONAF, uma vez que, garante a compra de parte da produção da agricultura familiar (JUNQUEIRA, 2008).

Os principais objetivos do PAA são: gerar renda e a sustentar preços à agricultura familiar; fortalecer as associações e cooperativas de agricultores familiares; incentivar o acesso a uma alimentação diversificada à população em situação de insegurança alimentar e nutricional. Além disso, procura valorizar a produção e a cultura alimentar das populações; promover a fixação das famílias no campo; dinamizar a economia local (pois aumenta a oferta de alimentos no mercado local e a gera maior número de postos de trabalho); promover formação de estoques de alimentos estratégicos; melhorar a qualidade dos produtos da agricultura familiar; incentivar o manejo agroecológico dos sistemas produtivos e/ou a agricultura orgânica, além de promover o resgate e preservação da biodiversidade (CONAB, 2003).

Os beneficiários do PAA são denominados fornecedores e consumidores: os fornecedores são agricultores familiares enquadrados no PRONAF, inclusive Povos e Comunidades Tradicionais (Decreto no 6.040, de 07.02.2007): extrativistas, quilombolas, famílias atingidas por barragens, trabalhadores rurais, e comunidades indígenas segundo a Portaria MDA $n^{\circ}$ 47, de 26.11.08; e os consumidores são instituições governamentais e não governamentais, que atendam populações em situação de insegurança alimentar e nutricional (CONB, 2003; CONAB, 2012).

Os equipamentos públicos de alimentação e nutrição, do tipo Bancos de Alimentos-BA visam intermediar, tanto o recebimento de doações de alimentos próprios para o consumo, destinadas às entidades de assistências sociais, como o processo de comercialização de alimentos entre os agricultores familiares e os beneficiários consumidores (em vulnerabilidade). Deste modo, estes adquirem produtos alimentícios com dispensa de licitação, de agricultores familiares, que historicamente sempre estiveram à margem das políticas públicas, destinando-os às pessoas em insegurança alimentar e nutricional, atendidas por programas sócioassistenciais. Os alimentos são recebidos (via doações de hipermercados, indústrias de alimentos ou comprados por meio do Programa Aquisição de Alimentos-PAA, Companhia Nacional de Abastecimento-Conab e outros), selecionados, divididos, processados ou não, embalados, e finalmente distribuídos gratuitamente às entidades sócio-assistenciais (BRASIL, 2003).

O PAA possui várias modalidades, porém a modalidade estudada foi de Compra Direta da Agricultura Familiar para Doação Simultânea (BRASIL, 2010). Está modalidade é operacionalizada pela CONAB, municípios e estados selecionados pela Secretaria Nacional de Segurança Alimentar e Nutricional-SESAN. Ela destinase à aquisição de alimentos provenientes da agricultura 
familiar, de origem agrícola, pecuária, extrativa, da indústria familiar atendendo assim, às demandas locais de suplementação alimentar e nutricional de creches, abrigos, albergues, asilos, escolas, hospitais públicos e dos programas sociais locais, tais como: bancos de alimentos, restaurantes populares e cozinhas comunitárias, resultando o desenvolvimento da economia local, o fortalecimento da agricultura familiar, a segurança alimentar e nutricional das pessoas beneficiárias, além de gerar trabalho e renda no campo (BRASIL, 2003; BRASIL 2010; GRIZA, 2011).

O trabalho teve como objetivo de caracterizar o perfil sócio demográfico e as atividades agrícolas de manejo e produção dos agricultores familiares, inscritos no Programa de Aquisição de Alimentos-PAA, do Banco de Alimentos-BA, do município de Ubá-MG.

\section{MATERIAL E MÉTODOS}

Tratou-se de um estudo transversal e descritivo realizado no ano de 2014, com agricultores familiares inseridos no Programa de Aquisição de Alimentos, do Banco de Alimentos, no município de Ubá-MG. Visto que, este é o único município da Zona da Mata Mineira que possui Equipamento Público do tipo Banco de Alimentos que intermedia a comercialização entre PAA e agricultores familiares.

A população estimada do município em 2013 foi de 108.493 habitantes. Em 2010 do total de 101.519 habitantes: $96,2 \%$ residiam na área urbana e o restante na área rural (CENSO DEMOGRÁFICO, 2010).

Participaram do estudo agricultores familiares de ambos os gêneros, com idade acima de 19 anos, incluindo adultos e idosos. O critério de inclusão consistiu na inserção do agricultor familiar no Programa de Aquisição de Alimentos, do Banco de Alimentos, do município de Ubá-MG. O cálculo da amostra considerou o número total de inscritos no PAA, do Banco de Alimentos, do município de Ubá-MG, em 2013 (população: 168 agricultores familiares; $\mathrm{N}=168$ ), $5 \%$ de erro tolerado e $95 \%$ para o nível de confiança, obtendo o tamanho amostral de 52 agricultores familiares. A este valor foi acrescido $10 \%$ prevendo perdas, assim resultando em 58 agricultores familiares, além disso, a prevalência conservadora foi de $30 \%$ (prevalência conservadora).

A seleção da amostra foi feita por meio de sorteio do número de cadastro dos agricultores familiares no
PAA até atingir 58 agricultores familiares (CALLEGARIJACQUES, 2003). Estes foram contactados pessoalmente recebendo todas as informações e esclarecimentos sobre a pesquisa e sobre o Termo de Consentimento Livre e Esclarecido-TCLE. Não houve rejeição em participar do estudo, e nem desistências ao longo do mesmo.

A pesquisa atendeu aos requisitos éticos, às diretrizes e às normas regulamentadoras de pesquisas com seres humanos propostos na resolução 466/2012 do Conselho Nacional de Saúde-CNS (CNS, 2012). O projeto foi submetido e aprovado pelo Comitê de Ética em Pesquisa da Universidade Federal de Viçosa-MG. O estudo teve inicio com os TCLE devidamente assinados pelos participantes, além de uma carta de Consentimento do Banco de Alimentos assinada pela nutricionista responsável e chefia imediata. O instrumento utilizado para coleta das informações, durante as entrevistas, com os agricultores familiares foi um questionário do tipo semiestruturado (RICHARDSON, 2007).

\section{Análise dos dados}

O banco de dados foi digitado e armazenado no Microsoft Office Excel 2010, para posterior análise, no software IBM SPSS versão 22. Foi realizada análise estatística descritiva conforme a característica dos dados, e os resultados foram expressos como frequência, média, mediana, desvio padrão, intervalo quartil, percentis, valores mínimo e máximo. A normalidade dos dados foi testada pelo gráfico de histograma e pelo teste de kolmogorov. O nível de confiança foi de $95 \%$ eá $<0,05$.

\section{RESULTADOS E DISCUSSÃO}

\section{Perfil sócio demográfico dos agricultores familiares}

Na Tabela 1 verifica-se que dos 58 agricultores familiares avaliados $(n=58)$, a média da idade foi de 48 anos, onde predominaram: a média do número de membros da família foi de quatro membros, o sexo masculino $67,24 \%(n=39)$, embora a maioria dos agricultores familiares tenham sido do sexo masculino observou-se neste estudo uma participação importante do sexo feminino, principalmente no cuidado com as hortaliças e com a produção de subprodutos dos alimentos cultivados. O empoderamento pode ser entendido como um processo que requer "transformação no acesso da mulher tanto aos bens quanto ao poder". Acredita-se que a apropriação destes aspectos permite a conquista de maior participação nas atividades ligadas 
Tabela 1 - Perfil sociodemográfico de agricultores familiares, inseridos no Programa de Aquisição de Alimentos (PAA) de um Banco de Alimentos, da Zona da Mata Mineira, Ubá (MG), 2014.

\begin{tabular}{|c|c|c|}
\hline Variáveis & $\mathrm{n}$ & $\%$ \\
\hline \multicolumn{3}{|l|}{ Sexo } \\
\hline Masculino & 39 & 67,20 \\
\hline Feminino & 19 & 32,80 \\
\hline \multicolumn{3}{|l|}{ Faixa etária } \\
\hline Adulta 19 À- 60 & 50 & 86,2 \\
\hline Idosos e" 60 & 8 & 13,8 \\
\hline \multicolumn{3}{|l|}{ Estado Civil } \\
\hline Casado & 51 & 87,9 \\
\hline Solteiro & 4 & 6,9 \\
\hline Divorciado & 1 & 1,7 \\
\hline Viúvo & 1 & 1,7 \\
\hline Outros & 1 & 1,7 \\
\hline \multicolumn{3}{|l|}{ Escolaridade } \\
\hline Analfabeto & 3 & 5,2 \\
\hline Ensino Fundamental* & 38 & 65,5 \\
\hline Ensino Médio* & 14 & 24,1 \\
\hline Ensino Superior & 3 & 5,2 \\
\hline \multicolumn{3}{|l|}{ Tipo de renda } \\
\hline Atividade Agrícola & 55 & 91,4 \\
\hline Atividade não Agrícola & 2 & 3,4 \\
\hline Aposentadoria & 3 & 5,2 \\
\hline \multicolumn{3}{|l|}{ Benefício } \\
\hline Ausente & 32 & 55,2 \\
\hline Bolsa Família & 6 & 10,3 \\
\hline Aposentadoria & 20 & 34,5 \\
\hline \multicolumn{3}{|l|}{ Propriedade } \\
\hline Própria & 41 & 70,7 \\
\hline Arrendada & 9 & 15,5 \\
\hline Outro** & 8 & 13,8 \\
\hline
\end{tabular}

Fonte: * Completo e incompleto; ** Comodato. Os números em negrito representam as maiores frequências.

à administração/produção/organização no meio rural, tanto no que se refere à efetivação de projetos desejados, quanto à autonomia nos processos decisórios (MENEGAT, 2010). Prevaleceu ainda a faixa etária adulta $86,2 \%(\mathrm{n}=50)$, casados $87,9 \%(\mathrm{n}=50)$, ensino fundamental $65,5 \%(\mathrm{n}=38)$. A maior parte da renda familiar $91,4 \%$ $(\mathrm{n}=55)$ origina-se da atividade agrícola, a qual é prioritária para o sustento da maioria dos agricultores familiares, mesmo entre os que recebem algum benefício do governo. A aposentadoria foi o benefício de maior frequência entre os participantes $34,5 \%(n=20)$. Com relação à apropriação da terra, a maioria $70,7 \%(n=41)$ produz em terra própria. Em relação ao impacto da comercialização via PAA na renda, a função agrícola é que sustenta da maioria das famílias participantes do programa, mesmo entre os que disseram que recebem algum outro tipo de benefício governamental (aposentadoria, pensão ou bolsa família) ou salário por atividades realizadas por algum membro da família fora da unidade de exploração agrícola (APAGATO, 2012).

A título de comparação, Em estudo realizado no município de Dracena-São Paulo, publicado por Hespandiol (2013) com agricultores familiares inseridos no PAA, verificou-se que todos os agricultores familiares eram proprietários rurais. A amostra constava com 60 agricultores familiares de ambos os sexos, sendo que os principais produtos comercializados com o PAA: café, acerola, banana, uva, mamão e coco verde, além de polpas de frutas para suco, e pão caseiro produzido pelas agricultoras. A maioria $85 \%$ era casada, a média do número de membros da família de quatro. A idade média de 50 anos e, na maioria $55 \%$, informaram ter concluído o ensino fundamental. A atividade agropecuária constituía-se a principal fonte de renda de $63,2 \%$ destes agricultores.

\section{Perfil de trabalho, práticas de produção e manejo dos agricultores familiares}

Em relação ao perfil da atividade agrícola dos agricultores familiares (Tabela 2 ), constatou-se que a maioria 86,2\% (n=50) dependia de mão de obra familiar para a condução de sua produção. Entretanto, 13,8\% $(n=8)$ dos agricultores familiares afirmaram contratar, em determinados períodos algum tipo de mão de obra ou serviço. Os alimentos produzidos pela maioria $94,8 \%$ $(n=55)$ destinam-se ao autoconsumo, associado com o fornecimento para o PAA e outros mercados. Além disso, $34,5 \%$ dos agricultores $(n=20)$ entregam seus alimentos também ao Programa Nacional de Alimentação Escolar-PNAE. Este programa é outra política pública de apoio à comercialização de produtos da agricultura familiar. Em um estudo com amostra de 75 agricultores familiares inseridos no PAA, do município de Campina do Monte Alegre, em relação ao perfil socioeconômico dos agricultores participantes do PAA, constatou-se que a maioria dependia exclusivamente do trabalho familiar (mulheres, filhos e, às vezes, irmãos) para a condução de sua produção, com nenhum dos entrevistados possuindo trabalhadores fixos contratados. Entretanto, dos 76 agricultores familiares $40,2 \%$ afirmaram contratar, em determinados períodos, algum tipo de mão de obra ou serviço, com destaque para atividades que exigem mecanização, como preparo de solo para o plantio. Quanto à forma de apropriação da terra, a 
Tabela 2 - Perfil de trabalho, práticas de produção e manejo, de agricultores familiares, inseridos no Programa de Aquisição de Alimentos (PAA) de um Banco de Alimentos (BA), da Zona da Mata Mineira. Ubá (MG), 2014.

\begin{tabular}{|c|c|c|}
\hline Variáveis & $\mathrm{n}$ & $\%$ \\
\hline \multicolumn{3}{|l|}{ Mão-de-obra } \\
\hline Familiar & 50 & 86,2 \\
\hline Familiar+Contratada & 8 & 13,8 \\
\hline \multicolumn{3}{|l|}{ Destino da Produção } \\
\hline Autoconsumo+PAA+Outros ${ }^{1}$ & 55 & $\mathbf{9 4 , 8}$ \\
\hline Auto consumo+PAA & 3 & 5,2 \\
\hline \multirow{2}{*}{\multicolumn{3}{|c|}{ PNAE }} \\
\hline & & \\
\hline Sim & 20 & 34,5 \\
\hline \multicolumn{3}{|l|}{ Tempo no BA } \\
\hline$<1$ ano & 4 & 6,9 \\
\hline $1+2$ anos & 8 & 13,8 \\
\hline $2+3 a n o s$ & 13 & 22,4 \\
\hline$\geq 3$ anos & 33 & 56,9 \\
\hline \multicolumn{3}{|l|}{ Ingresso no PAA-BA } \\
\hline Via EMATER & 34 & 58,6 \\
\hline Via BA & 1 & 1,7 \\
\hline Via outros Agricultores & 14 & 24,1 \\
\hline Outras & 9 & 15,5 \\
\hline \multicolumn{3}{|l|}{ Aração } \\
\hline Manual & 19 & 32,8 \\
\hline Trator/Micro trator & 36 & 62,1 \\
\hline Manual+Trator/Micro trator & 2 & 3,4 \\
\hline Outro & 1 & 1,7 \\
\hline \multicolumn{3}{|l|}{ Capina } \\
\hline Manual & 46 & 79,3 \\
\hline Mecânica & 6 & 10,3 \\
\hline Manual+Mecânica & 6 & 10,3 \\
\hline \multicolumn{3}{|l|}{ Banco de Sementes } \\
\hline \multirow{2}{*}{\multicolumn{3}{|c|}{ Policultivos }} \\
\hline & & \\
\hline Sim & 55 & 94,8 \\
\hline \multicolumn{3}{|l|}{ Uso de Agrotóxico } \\
\hline Sim & 43 & 74,1 \\
\hline \multicolumn{3}{|l|}{ Adubação } \\
\hline Química & 29 & 50 \\
\hline Verde e química & 14 & 24,1 \\
\hline Verde & 2 & 3,4 \\
\hline Orgânica & 3 & 5,2 \\
\hline Orgânica e verde & 1 & 1,7 \\
\hline Química e orgânica & 3 & 5,2 \\
\hline Todas & 6 & 5,2 \\
\hline \multicolumn{3}{|l|}{ Colheita } \\
\hline Manual & 51 & 87,9 \\
\hline Mecânica & 3 & 5,2 \\
\hline Manual+Mecânica & 4 & 6,9 \\
\hline \multicolumn{3}{|l|}{ Consórcio } \\
\hline Ausente & 43 & $\mathbf{7 4 , 1}$ \\
\hline Com animais & 1 & 1,7 \\
\hline Com leguminosas & 3 & 5,2 \\
\hline Frutíferas & 11 & 19 \\
\hline \multicolumn{3}{|l|}{ Irrigação } \\
\hline Chuva & 9 & 15,5 \\
\hline Mangueira & 15 & 25,9 \\
\hline Microaspersor & 28 & 48,3 \\
\hline Gotejamento & 3 & 5,2 \\
\hline Micro-aspersor+gotejador & 3 & 5,2 \\
\hline
\end{tabular}

${ }^{1}$ Outros $=$ Mercados de comercialização: feiras, CEASA e etc. Os números em negrito representam as maiores frequências. maioria $46 \%(n=35)$ produz em terra própria, sendo que desses $30 \%(n=23)$ ainda arrendam outras terras, enquanto $24 \%(n=18)$ dos entrevistados trabalham exclusivamente sob a condição de arrendatário ou meeiro (APAGATO, 2012).

$\mathrm{O}$ ingresso dos agricultores familiares no Banco de Alimentos para comercialização no PAA se deu em sua maioria 58,6\% $(n=34)$ via EMATER sendo que os outros ingressos foram via BA $1,7 \%$, por outros agricultores familiares $24,1 \%$ e outras formas $15,5 \%$. O tempo de comercialização da maioria dos agricultores familiares com o PAA é de mais de três anos.

Com relação às práticas de produção e manejo, observou-se: que 62,1\% $(n=36)$ realizavam aração com uso de trator ou micro trator para preparo da terra; que $79,3 \%(n=46)$ realizavam capina manual e que $87,9 \%$ $(n=51)$ realizavam colheita manual. A irrigação mais utilizada foi por micro aspersor com uma frequência de $48,3 \%(n=28)$, sendo que $25,9 \%$ por mangueiras, $15,5 \%$ por chuva, $5,2 \%$ por gotejamento e $5,2 \%$ outras formas de irrigação. Estes resultados mostram que a agricultura familiar também dispõe de tecnologias no processo de produção de seus alimentos, as quais também são empregadas na agricultura convencional. A diferença é que na agricultura familiar com bases agroecológicas o uso de máquinas e/ou implementos deve ser racional para que não cause impactos ambientais como a degradação e a poluição da terra, do solo e da água (APAGATO, 2012). Essas tecnologias devem ser capazes de ajudar a diversificar a produção de alimentos mais saudáveis, porém com ênfase na sustentabilidade econômica, ambiental e social.

Os participantes que relataram presença de banco de sementes e do policultivo foram: 32,8\% $(n=19)$ e $94,8 \%(n=55)$, respectivamente (Tabela 2$)$. O policultivo serve como exemplo de mudanças no contexto produtivo destes participantes, que tradicionalmente praticavam a monocultura de feijão e milho, e que hoje diversificam suas lavouras com cultivo de legumes e hortaliças, uma vez que, possuem mercado e preços garantidos para os seus alimentos.

O uso de agrotóxico infelizmente ainda é uma prática muito comum na agricultura e no presente estudo, a maioria dos agricultores familiares 71,4\% $(n=43)$ ainda realiza esta prática, estando expostos aos agrotóxicos e sujeitos às consequências dos mesmos. Porém, durante a pesquisa eles relataram que usam equipamentos de 
proteção individual nas aplicações e que seguem as orientações contidas nos rótulos. Há o desejo de produzir alimentos livres ou com o mínimo possível de agrotóxicos, uma vez que, a produção e o consumo de alimentos saudáveis são indicadores de boa qualidade de saúde e de vida. Cientes deste fato, alguns mencionaram preocupação com a qualidade e boa procedência de seus alimentos que são destinados ao autoconsumo e também às instituições sócias assistenciais que atendem crianças, idosos, enfermos e outros indivíduos em vulnerabilidade. O trabalho agrícola é uma das ocupações mais perigosas da atualidade. Dos riscos ocupacionais envolvidos nesta atividade destaca-se o uso de agrotóxicos que causa intoxicações agudas, doenças crônicas, problemas reprodutivos e danos ambientais (RECENA, 2008; FARIA, 2015).

Estima-se pela Organização Internacional do Trabalho, que os agrotóxicos causam anualmente cerca de 70 mil intoxicações agudas e crônicas fatais entre os trabalhadores rurais e um número muito maior de intoxicações não fatais, muitas vezes subnotificadas (SANTOS, 2012). Um dos fatores que colabora com a grande incidência de intoxicações por agrotóxicos é a facilidade de acesso e o grande número de produtos formulados com essas substâncias.

Além da exposição ocupacional, a contaminação alimentar e ambiental coloca em risco de intoxicação outros grupos populacionais, merecendo destaque as famílias dos agricultores, a vizinhança da unidade produtiva e a população em geral, que consome o que é cultivado no campo. Sendo assim, é urgente desestimular esta prática tão nociva ao homem e aos agroecossistemas, por meio de ações educativas como palestras, treinamentos e capacitações sobre o tema que podem contribuir como medidas de segurança ocupacional e também de segurança alimentar e nutricional dos agricultores familiares, de suas famílias e de toda cadeia de produção e consumo dos alimentos.

O tipo de adubação mais frequente $50 \%(n=29)$ entre estes agricultores foi a adubação química. A exposição aos adubos químicos podem causar intoxicações graves e letais, envolvendo produtos fosfatados, sais de potássio e nitrato. As intoxicações por fosfatos causam hipocalcemia, enquanto as causadas por sais de potássio provocam ulceração da mucosa gástrica, hemorragia, perfuração intestinal e outras. Já os nitratos se transformam no organismo em nitrosaminas que são cancerígenas (SILVA, 2005). No presente estudo $24,1 \%(n=14)$ dos agricultores familiares relataram realizar a combinação de adubação química com adubação verde, e 3,4\% (n=2) relataram realizar somente a adubação verde. Os agricultores familiares (principalmente os que cultivam bananas e outras frutíferas) relataram usar os restos das capinas e das podas de suas culturas para aproveitamento como adubação verde. Esta prática de adubação verde deve ser estimulada podendo contribuir para melhorar diretamente a segurança ocupacional e alimentar dos agricultores e de seus familiares, e indiretamente a saúde dos consumidores finais dos alimentos produzidos.

A maior parte da amostra $74,1 \%(n=43)$ não faz o consórcio de culturas, mas dos agricultores familiares que realizam esta prática $19 \%$ ( $\mathrm{n}=11)$ fazem o consórcio com frutíferas. Alguns fornecem frutas ao PAA, outros somente usam para o autoconsumo, além disso, existem também aqueles agricultores familiares que vendem as frutas inadequadas para a comercialização e para o consumo "in natura" para as agroindústrias de suco da região.

Os agricultores fazem uso de algumas práticas de produção e de manejo agroecológicas, que se estimuladas e mantidas ao longo do tempo, podem contribuir para construção de sistemas agrícolas autossustentáveis e diversificados com baixa utilização de insumos industriais e uso eficiente de energia, podendo também contribuir para o equilíbrio dos agroecossistemas. Alguns estudos sobre produção e práticas agroecológicas concluíram que neste modelo de produção existe uma diversidade maior de alimentos comparado à produção convencional. Sendo assim, aAgroecologia pode colaborar com a segurança alimentar e nutricional dos agricultores familiares (BRANCO, 2004; SERRANO, 2012).

\section{CONCLUSÕES}

O presente estudo mostrou que a amostra representativa dos agricultores familiares participantes do PAA de um Banco de Alimentos, da Zona da Mata Mineira caracteriza-se por indivíduos de ambos os sexos, com predomínio do sexo masculino, faixas etárias de adultos e idosos, nível de escolaridade de ensino fundamental e estado civil casada. Embora a maioria dos agricultores familiares tenham sido do sexo masculino observou-se neste estudo uma participação importante 
do sexo feminino, principalmente no cuidado com as hortaliças e com a produção de subprodutos dos alimentos cultivados, como bolos, doces e polpas para sucos.

A maioria depende da mão-de-obra familiar, e o destino da sua produção é o autoconsumo, a comercialização com PAA e outros mercados locais. Quanto à forma de apropriação a maioria tem a posse da terra.

Com relação às práticas de produção e manejo a colheita e a capina manuais se destacam. O uso da tecnologia e da modernização também está presente na agricultura familiar como, por exemplo, a irrigação e a aração, mas na agricultura com bases agroecológicas esse uso deve ser mais racional para que não cause impactos ambientais como a degradação e a poluição da terra, do solo e da água.

O uso de agrotóxicos e de adubos químicos ainda é uma prática muito comum na agricultura familiar, além da exposição ocupacional, a contaminação alimentar e ambiental coloca em risco de intoxicação outros grupos populacionais, merecendo destaque as famílias destes agricultores familiares, a vizinhança da unidade produtiva e a população em geral, que consome o que é cultivado no campo. Esforços oriundos das três esferas de poder público juntamente com representantes dos agricultores familiares e da sociedade civil devem ser feitos para melhorar as condições de trabalho e de saúde dos agricultores e de todos os atores envolvidos neste sistema agroalimentar.

\section{LITERATURA CITADA}

AGAPATO, J.P.; BORSATTO, R.S.; ESQUERDO, V.F.S.; BERGAMASCO, S.M.P.P. Avaliação do programa de aquisição de alimentos (PAA) em Campina do Monte Alegre, estado de São Paulo, a partir da percepção dos agricultores. São Paulo. Informações Econômicas, v.42, n.2, 2012.

ALTIERI, A.M. Agroecologia: A dinâmica produtiva da agricultura sustentável. 4 a edição-Porto Seguro: Editora da UFRGS, 1989.

BRANCO, C.T.; MARRA, F.J. A agroecologia promovendo segurança alimentar: um estudo de caso no semi-arido brasileiro. Rio de Janeiro.

Revista Agriculturas, v.1, p.15-21, 2004.
BRASIL. Programa de Aquisição de Alimentos-PAA. Caderno Base III. Seminário Nacional PAA. Brasília: MDA, 2010.

BRASIL. Lei n. 10696, de 2 de julho de 2003. Dispõe sobre a repactuação e o alongamento de dívidas oriundas de operações de crédito rural, e dá outras providências. Diário Oficial da União, Seção 1, Poder Executivo, Brasília, 3 jul. 2003. Seção 1. Disponível e <http.planalto.gov.br?ccivil_03/Leis/ 2003/110.696. htm>. Acesso: em 11 abr. 2014.

BRASIL. Lei n ${ }^{\circ} 11.346$, de 15 de setembro de 2006. Lei Orgânica de Segurança Alimentar e Nutricional. Dispõe sobre Criação do Sistema Nacional de Segurança Alimentar e Nutricional, 2006a.

CALLEGARI-JACQUES, S.M. Bioestatística: princípios e aplicações/ Sidia M. Callegari-Jacques. Porto Alegre: Artmed, 2003.

CARNEIRO, F.F.; PIGNATI, W.; RIGOTTO, R.M.; AUGUSTO, L.G.S.; RIZOLLO, A.; MULLER, N.M.; ALEXANDRE, V.P.; FRIEDRICH, K.; MELLO, M.S.C. Dossiê ABRASCO-Um alerta sobre os impactos dos agrotóxicos na saúde. ABRASCO, Rio de Janeiro, $1^{\text {a }}$ Parte. 98p, 2012.

CERQUEIRA, P.S.; ROCHA, A.G.; COELHO, V.P. Agricultura familiar e políticas públicas: algumas reflexões sobre o Programa de Aquisição de Alimentos no estado da Bahia. Revista Desenbahia, v.3, p.55-78, 2006. Disponível em:<http// www.mesteco. ufba.br/scripts/arquivos/ at_ecoreg_05.pdf.>. Acesso em 06 mai. 2015.

COMPANHIA NACIONAL DE ABASTECIMENTOCONAB-Programa de Aquisição de Alimentos-PAA: A evolução do PAA no período de 2003 e 2012. Disponível em http://www.conab.gov.br/OlalaCMS/ Acesso em: 10 de março de 2014.

COMPANHIA NACIONAL DE ABASTECIMENTOCONAB-Programa de Aquisição de Alimentos-PAA: Ações da Conab em 2003. Disponível em http:// www.conab.gov.br/OlalaCMS/uploads/arquivos/ Acesso em: abril de 2014

FARIA, N.M.X.; FASSA A.G.; FACCHINI L.A. Intoxicação por agrotóxicos no Brasil: os sistemas oficiais de informação e desafios para realização de estudos epidemiológicos. Disponível em: <http:// www.scielosp.org/scielo>. Acesso em 14 mai. 2015. 
GRISA, C.; SCHMITT, C.J.; MATTEI, L.F.; MALUF, R.S.; LEITE, S.P. Contribuições do Programa de Aquisição de Alimentos à segurança alimentar e nutricional e à criação de mercados para a agricultura familiar. Agriculturas, v. 8 , n.3, 2011.

HESPANHOL, R.A.M. Programa de Aquisição de Alimentos: Limites e potencialidades de políticas de segurança alimentar para a agricultura familiar. Uberlândia, Sociedade \& Natureza, v.25, n.3, p.469-483, 2013.

IBGE-Instituto Brasileiro de Geografia e Estatística. Censo Demográfico 2010. http:/ /www.censo2010.ibge.gov.br/sinopse/ index.php?uf=31\&dados=29. Acesso em 05 de maio de 2014.

JUNQUEIRA, C.P.; LIMA, J.F. de. Políticas públicas para a agricultura familiar no Brasil. Londrina. Semina: Ciências Sociais e Humanas, v.29, n.2, p.159-176, 2008.

LEI DE CRIAÇÃO: Lei número 10.696, de 2 de julho de 2003 (artigo 19): Programa de Aquisição de alimentos-PAA. http:// www.planalto.gov.br/ccivil-03/leis/2003/L 10.696. htm. Acesso em: março 2014.

LEI N ${ }^{\circ}$ 7.802: Agrotóxicos. De 11 de julho de 1989. www.planalto.gov.br/ccivil03/ lis/17802.htm. Acesso em 16 de maio de 2014.

MALUF, R.S.J. Segurança Alimentar e Nutricional. Petrópolis, RJ, Editora Vozes, 2007.

MEIRELLES, L.C. Controle de agrotóxicos: estudo de caso do Estado do Rio de Janeiro, 1985/1995. Dissertação de mestrado. Programa de Pós-graduação de Engenharia da Universidade Federal do Rio de Janeiro, Rio de Janeiro, 1996.

MENEGAT, A.S.; FARIAS, M.F.L. PRONAF MULHER: Perspectivas para o empoderamento feminino nos assentamentos rurais do Estado de Mato Grosso do Sul. VII CONGRESSO LATINO AMERICANO DE SOCIOLOGIARURALPorto de Galinhas, 2010.
MINAYO, M.C.S. O desafio do conhecimento: pesquisa qualitativa em saúde. Abrasco. Editora Hucitec. 11 ${ }^{\mathrm{a}}$ Edição, 1992.

NETO, M.P.N. O Programa de Aquisição de Alimentos-PAA, no município de Lagoa Seca-PB-Análise das transformações vivenciadas na agricultura familiar. Dissertação de mestrado. Universidade Estadual do Paraíba. Campina Grande-PB, 2012.

NEUMANN, A.I.C.P.; MARTINS, I.S.; MACOPITO, L.F.; ARAÚJO, E.A.C. Padrões alimentares associados a fatores de risco cardiovascular entre residentes de um município brasileiro. Pan Americam Journal Public Health, v.22, n.5, 2007.

RECENA, M.C.P.; CALDAS, E.D. Percepção de risco, atitudes e práticas no uso de agrotóxicos entre agricultores de Culturama, MS. São Paulo. Revista de Saúde Pública, v.42, n.2, 2008.

RESOLUÇÃO DO CONSELHO NACIONAL DE SAÚDE-CNS 466/12. Diretrizes e normas regulamentadoras de pesquisas envolvendo seres humanos. http:// www.conselho.saude.gov/resolucoes/2012/ Reso466pdf/96.htm. Acesso em 05 de maio de 2014.

RICHARDSON, R.J. Pesquisa Social: Métodos e técnicas. $3^{a}$ Ed. São Paulo: Atlas, 2007.

SANTOS, A.T. "Agricultura familiar e programa de aquisição de alimentos: uma análise de sua implantação no Município de Ponta Grossa”. p.129, Dissertação-Universidade Estadual de Ponta Grossa, Ponta Grossa, 2010.

SANTOS, M.E.; SANTOS, H.C.; DANTAS, H.J. O uso indiscriminado de agrotóxico na agricultura familiar no assentamento Aroeira no município de Santa Terezinha-PB. VII CONNEPI-VII Congresso Norte Nordeste de Pesquisa e Inovação, 2012. 
SILVA, J.M.; NOVATO-SILVA, E.; FARIA, H.P.; PINHEIRO, T.M.M. Agrotóxico e trabalho: uma combinação perigosa para a saúde do trabalhador rural. Rio de Janeiro. Ciência \& Saúde Coletiva, v.10, n.4, 2005.

SILVA, S.G. Territorialidade, Agricultura Familiar e Agroecológica: Uma análise introdutória do Programa de Aquisição de Alimentos (PAA) na demanda

territorial de 2008. Porta de Galinhas, 2010.
VOGT, S.P.C.; SOUZA, R.S. de. Mercados institucionais locais como instrumento de fortalecimento da agricultura familiar: uma análise do Programa de Aquisição de Alimentos na Região Celeiro-RS. In: Congresso da Sociedade Brasileira de Economia, Administração e Sociologia Rural, v.47, 2009. Porto Alegre. Anais. Disponível em: < http:// www.sober.org.br/palestra/13/743.pdf $>$. Acesso em 06 mai. 2015.

${ }^{1}$ Recebido para publicação em 04/10/2015 e aprovado em 14/12/2015. 